\title{
The aldehyde dehydrogenase enzyme 7A1 is functionally involved in prostate cancer bone metastasis
}

\author{
Christel van den Hoogen • Geertje van der Horst • \\ Henry Cheung • Jeroen T. Buijs • Rob C. M. Pelger • \\ Gabri van der Pluijm
}

Received: 5 February 2011/ Accepted: 23 May 2011/Published online: 7 June 2011

(C) The Author(s) 2011. This article is published with open access at Springerlink.com

\begin{abstract}
High aldehyde dehydrogenase (ALDH) activity can be used to identify tumor-initiating and metastasis-initiating cells in various human carcinomas, including prostate cancer. To date, the functional importance of ALDH enzymes in prostate carcinogenesis, progression and metastasis has remained elusive. Previously we identified strong expression of ALDH7A1 in human prostate cancer cell lines, primary tumors and matched bone metastases. In this study, we evaluated whether ALDH7A1 is required for the acquisition of a metastatic stem/progenitor cell phenotype in human prostate cancer. Knockdown of ALDH7A1 expression resulted in a decrease of the $\alpha 2^{\mathrm{hi}} / \alpha \mathrm{v}^{\mathrm{hi}} / \mathrm{CD} 44^{+}$ stem/progenitor cell subpopulation in the human prostate cancer cell line PC-3M-Pro4. In addition, ALDH7A1 knockdown significantly inhibited the clonogenic and migratory ability of human prostate cancer cells in vitro. Furthermore, a number of genes/factors involved in migration, invasion and metastasis were affected including transcription factors (snail, snail2, and twist) and osteopontin, an ECM molecule involved in metastasis. Knockdown of ALDH7A1 resulted in decreased intra-bone growth and inhibited experimentally induced (bone) metastasis, while intra-prostatic growth was not affected. In line with
\end{abstract}

Electronic supplementary material The online version of this article (doi:10.1007/s10585-011-9395-7) contains supplementary material, which is available to authorized users.

C. van den Hoogen · G. van der Horst · H. Cheung .

J. T. Buijs · R. C. M. Pelger · G. van der Pluijm ( $\square)$

Department of Urology, Leiden University Medical Centre,

J3-100, Albinusdreef 2, 2333 ZA Leiden, The Netherlands

e-mail: G.van_der_Pluijm@lumc.nl

G. van der Pluijm

Department of Endocrinology, Leiden University Medical

Centre, Albinusdreef 2, 2333 ZA Leiden, The Netherlands these observations, evidence is presented that TGF- $\beta$, a key player in cancer invasiveness and bone metastasis, strongly induced ALDH activity while BMP7 (an antagonist of TGF- $\beta$ signaling) down-regulated ALDH activity. Our findings show, for the first time, that the ALDH7A1 enzyme is functionally involved in the formation of bone metastases and that the effect appeared dependent on the microenvironment, i.e., bone versus prostate.

Keywords Prostate cancer - Bone metastasis - ALDH · EMT $\cdot$ Tumor-initiating cells

$\begin{array}{ll}\text { Abbreviations } \\ \text { ALDH } & \text { Aldehyde dehydrogenase } \\ \text { BLI } & \text { Whole body bioluminescent reporter imaging } \\ \text { BMP } & \text { Bone morphogenetic protein } \\ \text { CSC } & \text { Cancer stem cell } \\ \text { EMT } & \text { Epithelial-to-mesenchymal transition } \\ \text { GAPDH } & \text { Glyceraldehyde-3'-phosphate } \\ & \text { dehydrogenase } \\ \text { OPN } & \text { Osteopontin } \\ \text { SDS-PAGE } & \text { Sodium dodecyl sulphate-polyacrylamide } \\ & \text { gel electrophoresis } \\ \text { shRNA } & \text { Short hairpin RNA } \\ \text { TGF- } \beta & \text { Transforming growth factor- } \beta\end{array}$

\section{Introduction}

Prostate cancer metastatic disease, often occult at time of diagnosis or surgery, is increasingly linked to mortality. Secondary lesions are mostly found in the skeleton, indicating bone as preferred site for the growth of disseminated disease [1]. Understanding the mechanisms of prostate 
cancer metastasis is essential for the development of novel therapies and detection methods.

Acquisition of an invasive phenotype of cancer cells is a requirement for bone metastasis; transformed epithelial cells can switch to a motile, mesenchymal phenotype by epithelial-to-mesenchymal transition (EMT) [2, 3]. Accumulating evidence suggests that EMT may generate cancer cells with properties of tissue stem cells [4-8]. Prostate cancer cells with a stem/progenitor phenotype are believed to be critically involved in prostate cancer initiation and progression and recent evidence from our group also indicated that this subpopulation of cancer cells is involved in bone metastasis formation [4-8].

An increasing number of studies support the notion that the primary tumor is maintained by a small number of cells, the cancer stem cells (CSCs) or tumor-initiating cells (TICs). It is generally believed that cellular heterogeneity in primary prostate cancers also arises from this subpopulation with stem/progenitor characteristics [4, 7, 9-11].

Because of the heterogeneous nature of solid cancers, the reliability of cell surface markers as the sole way to isolate TICs has remained controversial [4, 11-16]. A complementary strategy for identifying TICs involves measurement of aldehyde dehydrogenase (ALDH) activity. $\mathrm{ALDH}$ is a detoxifying enzyme which has important functions in the development of epithelial homeostasis, and as a result, deregulation of this class of enzymes has been implicated in multiple cancers [17]. ALDH activity is involved in detoxification, drug resistance, cell proliferation, differentiation, and response to oxidative stress [1821]. It is becoming increasingly clear that ALDH activity can be used, either alone or in combination with cell surface markers, to identify TICs [4, 22-26]. In a recent study, we showed that human prostate cancer cells with high ALDH activity are enriched for tumor- and metastasisinitiating cells [4]. This ALDH $^{\text {hi }}$ subpopulation showed increased clonogenic and migratory ability in vitro and enhanced tumorigenic and metastatic ability in vivo. At present, it is not clear whether different ALDH isoforms contribute to the high ALDH activity observed in highly tumorigenic and metastatic prostate cancer cells. The reagent ALDEFLUOR $^{\mathrm{TM}}$ that is frequently used for viable cell sorting based on ALDH activity has only been validated for ALDH1 and ALDH3 and not for the remaining 17 ALDH enzymes [17]. The prognostic significance of ALDH1 expression has been reported in a number of epithelial tumors, but the role of other ALDH enzymes in prostate cancer has not been addressed to date [22, 23, 2631].

Previously, we found high levels of ALDH7A1 in various prostate cancer cell lines and primary cultures. Strong ALDH7A1 immunolocalization was also observed in primary prostate cancer tissue and matched bone metastases
[4]. The functional involvement of ALDH7A1 in prostate cancer progression and metastasis has not been addressed.

In this paper we investigated the role of ALDH7A1 in prostate cancer initiation, progression, and bone metastasis formation by generating prostate cancer cells with stable knockdown of ALDH7A1. Our findings indicate that ALDH7A1 is involved in bone metastasis formation and that the functional involvement of ALD7A1 is dependent on the tumor microenvironment. Furthermore, the observed differences in the size of prostate cancer stem/progenitor subpopulations reflects the previously found opposite role of TGF- $\beta$ and BMP7 on experimentally induced metastasis [32].

\section{Results}

Generation of prostate cancer cells with stable ALDH7A1 knockdown

A potential strategy for the identification and isolation of cells with a stem cell-like phenotype in hematological and a number of epithelial malignancies involves selection based on ALDH enzyme activity [4, 23, 33] using the ALDEFLUOR $^{\circledR}$ assay. We have previously shown that various $\mathrm{ALDH}$ isoforms are expressed in human prostate cancer, all of which can theoretically contribute to the observed ALDEFLUOR activity [4]. One of the ALDH enzymes, ALDH7A1, was strongly expressed in various prostate cancer cell lines, primary cultures and in primary prostate cancer tissue with matched bone metastases [4]. In the present study, we investigated the effects of blocking ALDH7A1 activity on prostate cancer growth and (bone) metastasis by using lentiviral short hairpin RNA interference.

Different shRNAi constructs from the Sigma MISSION library were used to knockdown ALDH7A1 activity and two constructs showed a strong down-regulation of ALDH7A1 compared to the non-targeted control prostate cancer cells (Fig. 1a cell clone \#1 and \#2). Based on the high level of knockdown, we selected cell clone \#1 (ALDH7A1-kd-Pro4luc) for further characterization in vitro and functional analysis in vivo and compared all results to the non-targeted control prostate cancer cells (NT-Pro4luc). Cell viability was confirmed by trypan blue exclusion prior to each experiment, and no differences among experimental groups were observed (data not shown). Potential impact on other ALDH isoforms was investigated by q-PCR analysis (Supplemental Figure S1). The expression levels of the ALDH isoforms 3A2, 5A1, 9A1 and 18A1 were not significantly affected by the ALDH7 knock down, whereas the expression levels of ALDH4A1 and 6A1 displayed a minor increase. 
Fig. 1 Characterization of ALDH7A1-kd-Pro4luc prostate cancer cells. a Western blot analysis of ALDH7A1 expression in NT-Pro4luc (first lane) and ALDH7A1-kdPro4luc cells (cell clone \#1 and \#2 derived from different shRNAi constructs). b The number of colonies per 96-well plate in the single cell diluted cultures after 2 weeks in the ALDH7A1-kd-Pro4luc and NTPro4luc cells. $\mathbf{c}$ Mean number of migrated ALDH7A1-kdPro4luc and NT-Pro4luc cells per field. d Absorbance measured at $490 \mathrm{~nm}$ after 24 , 48 , and $72 \mathrm{~h}$ of incubation in ALDH7A1-kd-Pro4luc (filled circle) and control NT-Pro4luc cells (open circle). Data are representative for three independent experiments
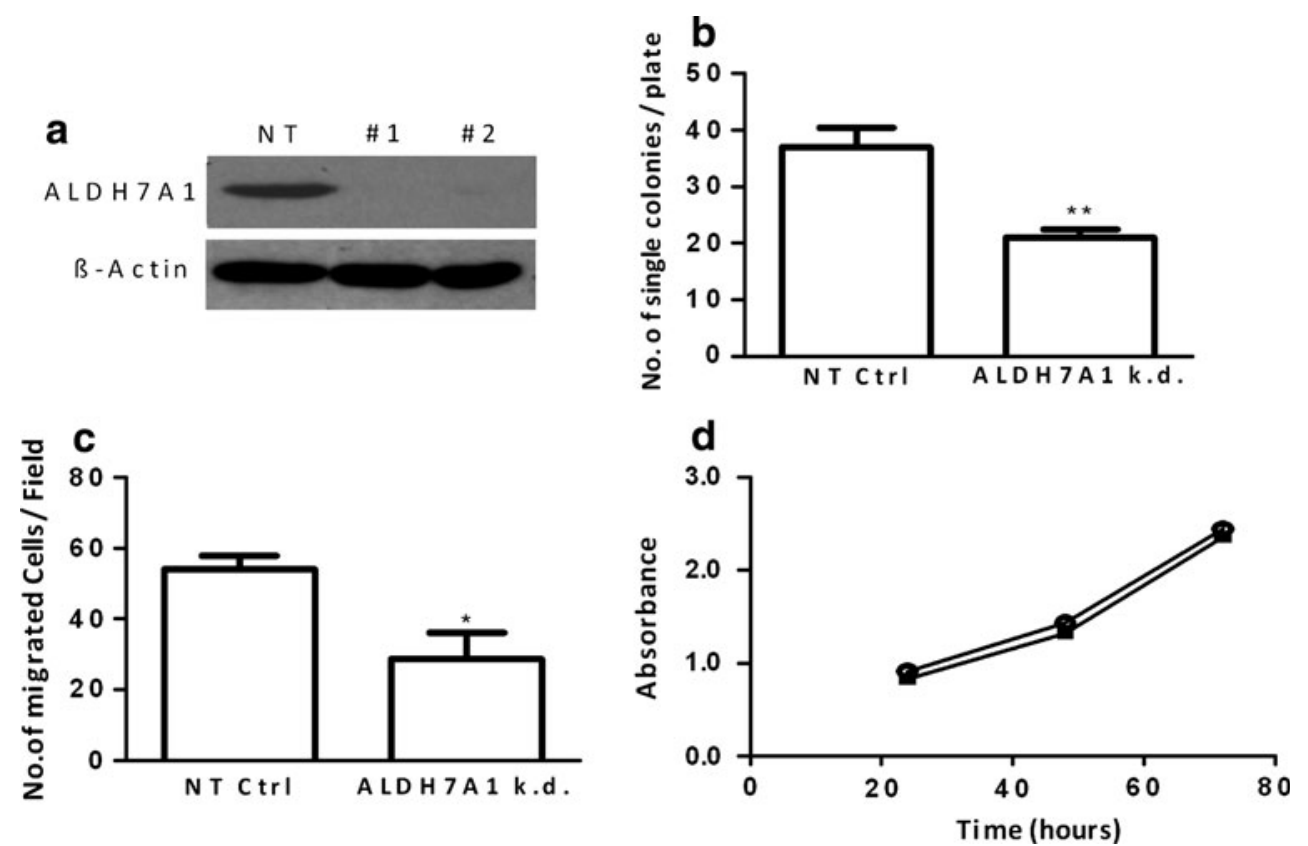

Effects of ALDH7A1 knockdown on clonogenicity, cellular invasion and cancer stem/progenitor characteristics

Selection of cells based on high ALDH activity can be used to enrich for prostate cancer cells with a stem/progenitor cell phenotype, thus linking ALDH activity (ALDEFLUOR) to stem/progenitor phenotypes [4, 23]. ALDH7A1 knock down resulted in a $21 \%$ decrease in ALDH activity as measured with the ALDEFLUOR assay $(100 \% \pm 1$ vs. $79 \% \pm 13$ for, respectively the NT-Pro4luc and ALDH7A1-kd-Pro4luc cells). This link is further illustrated by the fact that stable knockdown of ALDH7A1 led to significantly decreased clonogenicity compared to NT-Pro4luc control cells (Fig. 1b). Furthermore, stable knockdown of ALDH7A1 resulted in a strongly impaired migratory response in a Boyden Chamber assays (Fig. 1c). Blocking the activity of ALDH7A1 in PC-3M-Pro4luc cells did not affect their proliferation rates at various time points (Fig. 1d).

Upon stable ALDH7A1 knockdown, a concomitant decrease in previously identified prostate cancer stem/ progenitor cell surface markers was observed (Fig. 2a). Furthermore, ALDH7A1 knockdown in prostate cancer cells, led to reduced expression of $E$-cadherin transcriptional repressors (snail, snail2 and twist) and pro-metastatic factors including $N$-cadherin, twist, and osteopontin (OPN)
(Fig. 2a) [34, 35]. In line with these observations, the $E$-cadherin/vimentin ratio increased upon ALDH7A1 knockdown, indicating the generation of a more epithelial and less invasive cell phenotype (Fig. 2b).

ALDH7A1 knockdown in prostate cancer cells differentially affects orthotopic and intra-bone growth in preclinical models

Our in vitro data showed that prostate cancer cells with a strongly diminished ALDH7A1 activity are poorly clonogenic and display a more sessile, epithelial phenotype compared with control cells. Subsequently, we analyzed and compared the tumorigenic and metastatic potential of both cell lines in vivo.

When implanted orthotopically in the mouse prostate, no significant differences were observed in tumor growth between both groups (Fig. 3a). Strikingly, we observed marked differences in tumorigenicity and metastatic ability in bone/bone marrow using our preclinical models of intrabone growth [4, 32, 36]. Tumor take and intra-bone tumor growth were significantly decreased in the ALDH7A1kd-Pro4luc group versus NT-Pro4luc control cells (Fig. 3b).

Inoculation of cancer cells into the left cardiac ventricle of immunodeficient mice is a widely used animal model of bone metastasis $[4,32,36]$. Significant differences in tumor 

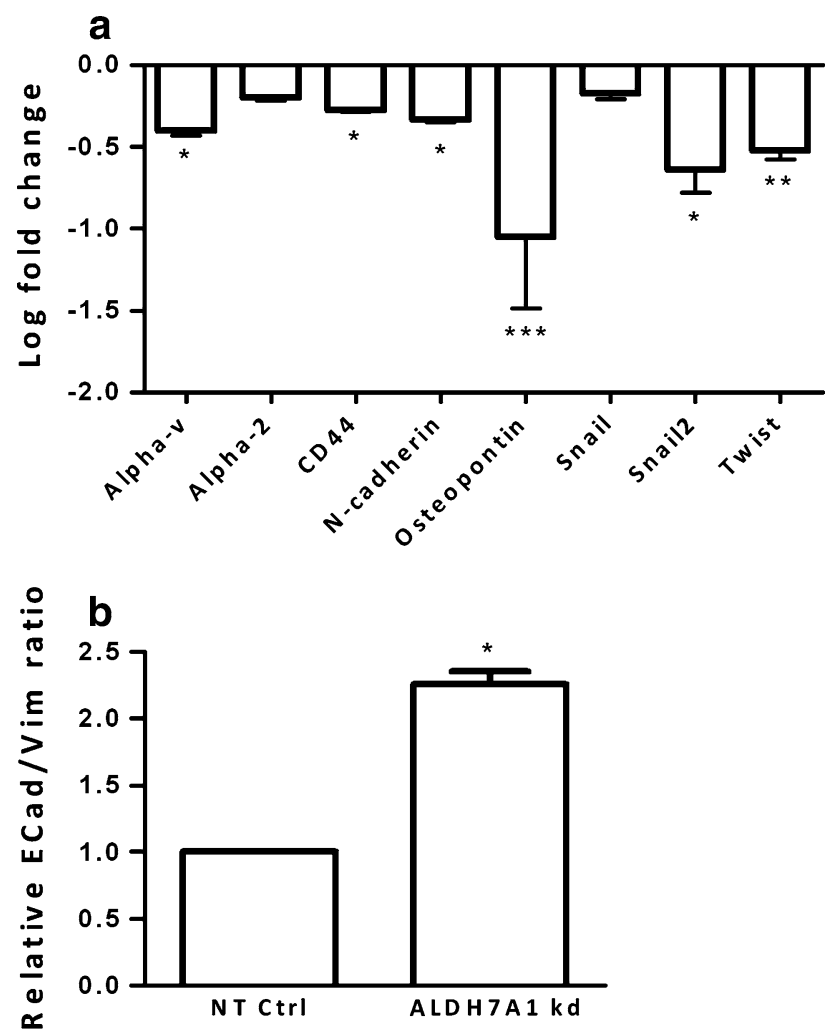

Fig. 2 Differential expression of stem/progenitor markers and invasiveness-associated genes upon ALDH7A1 expression knockdown. a q-PCR analysis of stem/progenitor cell markers and EMT-associated genes ( $\alpha \mathrm{v}, \alpha 2, \mathrm{CD} 44$, osteopontin, $N$-cadherin, snail, snail2, and twist). Relative expression levels in ALDH7A1-kd-Pro4luc cells were shown as compared to the NT-Pro4luc control cells. All values were normalized for GAPDH and presented as mean \pm sem. b Relative $E$ cadherin/vimentin ratios of ALDH7A1-kd-Pro4luc and NT-Pro4luc control cells as measured by q-PCR analysis. Data are representative for two independent experiments

growth and metastasis formation were observed (Fig. 4). In line with our intra-bone model, the ALDH7A1-kd-Pro4luc cells failed to reproducibly generate bone metastases, although limited growth was observed occasionally (Fig. 4a). Furthermore, metastatic tumor burden was significantly lower in the ALDH7A1-kd-Pro4luc group compared with the NT-Pro4luc control cells (Fig. 4b). Moreover, the total number of (bone) metastases was significantly decreased in the mice injected with the ALDH7A1 knockdown cells (Fig. 4c, d).

Regulation of the size of PC-3M-Pro4luc stem/ progenitor subpopulation

The TGF- $\beta$ superfamily (including TGF- $\beta$ s and BMPs) plays a key role in EMT (tumor invasiveness), generation of cancer stem cells, and bone metastasis. Our group described previously that TGF- $\beta$ and BMP7 have opposite roles in oncologic EMT, where BMP7 can counteract TGF$\beta$ induced EMT and inhibit bone metastasis $[7,8,32]$.

Incubation with different concentrations of TGF- $\beta$ for $72 \mathrm{~h}$ significantly and dose-dependently increased the size of the $\mathrm{ALDH}^{\mathrm{hi}}$ subpopulation of prostate cancer stem/ progenitor cells, whereas incubation with different concentrations of BMP7 significantly and dose-dependently decreased the size of this subpopulation (Fig. 5a). Incubation with BMP2, BMP4, and BMP7 decreased the size of the $\mathrm{ALDH}^{\mathrm{hi}}$ subpopulation significantly $(-56,-62$, and $-67 \%$, respectively), while the close homolog of BMP7, BMP6, only marginally affected this subpopulation with $-25 \%$ (Fig. 5b).

Subsequently, we analyzed whether BMPs and TGF- $\beta$ affected the mRNA expression level of ALDH7A1 in PC-3M-Pro4luc prostate cancer cells. In line with the data shown in Fig. 5a and $\mathrm{b}$ we found that incubation with TGF$\beta$ for $72 \mathrm{~h}$ significantly increased the ALDH7A1 mRNA expression level by 2.5 fold (Fig. $5 \mathrm{c}$ ). In addition to TGF$\beta$, ALDH7A1 expression was inhibited upon incubation for $72 \mathrm{~h}$ with BMP2, 4, 6, and BMP7 (2.3 fold; 3.5 fold; 1.3 fold; and 5.0 fold inhibition, respectively). These q-PCR data were confirmed by Western blot analysis ( 2.5 fold increase upon TGF-stimulation; Fig. 5d.).

\section{Discussion}

Once prostate cancer has spread to the skeleton, treatment options are mainly focused on palliation and the prevention of fractures. Due to the observed heterogeneity in primary tumors and metastases, it has been a major challenge to distinguish and select prostate cancer cells with tumor- and metastasis-initiating ability. The functional identification of metastasis-initiating cells is a prerequisite for properly targeted therapy of metastatic disease in advanced prostate cancer.

It is becoming increasingly clear that ALDH activity $\left(\right.$ ALDEFLUOR $^{\mathrm{TM}}$ ) can be used, either alone or in combination with other cell surface markers, to identify tumorinitiating cells (TICs) in multiple carcinomas [22-26]. In addition, we have shown recently that high ALDH activity could be used to select for prostate cancer cells with increased metastatic ability [4]. This was confirmed by $\mathrm{Yu}$ et al. [37] using subcutaneous implantations of prostate cancer cells. Moreover, we found differential expression of various ALDH isoforms in human prostate cancer, with high expression of ALDH7A1 in several cell lines, primary cultures, and primary prostate tissue with matched bone metastases. This suggests that, besides the ALDH1 enzyme which has been reported to be important in a number of epithelial tumors $[22,23,26,27,30,31]$, other ALDH isoforms may contribute to the overall ALDH activity and 
a

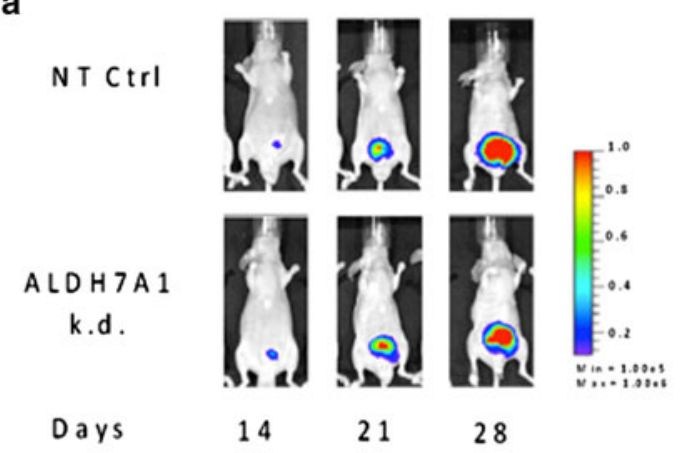

b

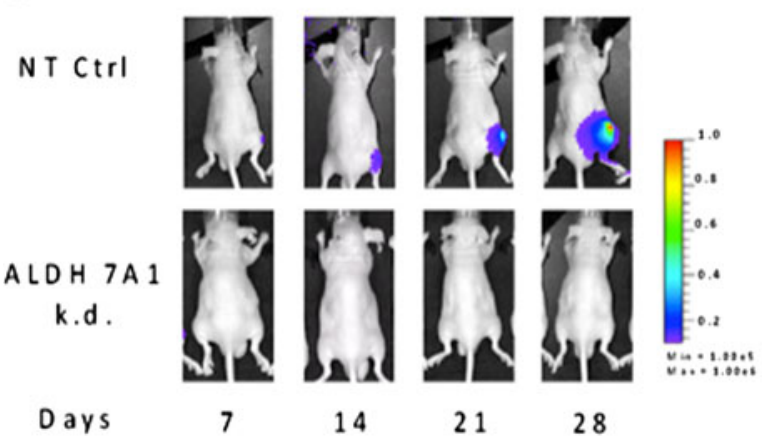

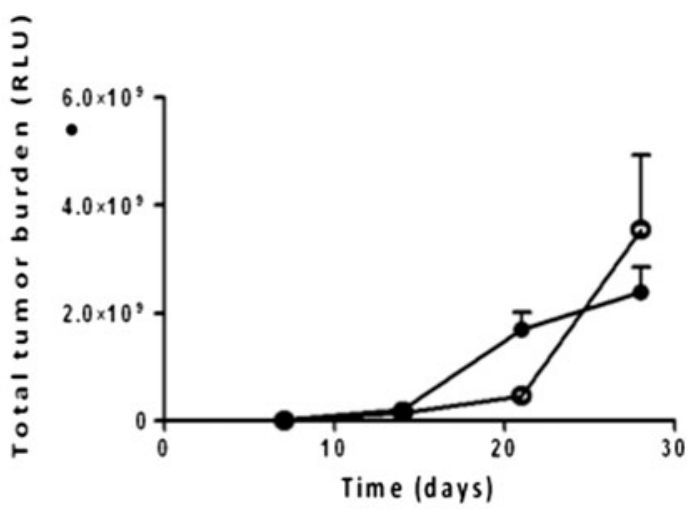

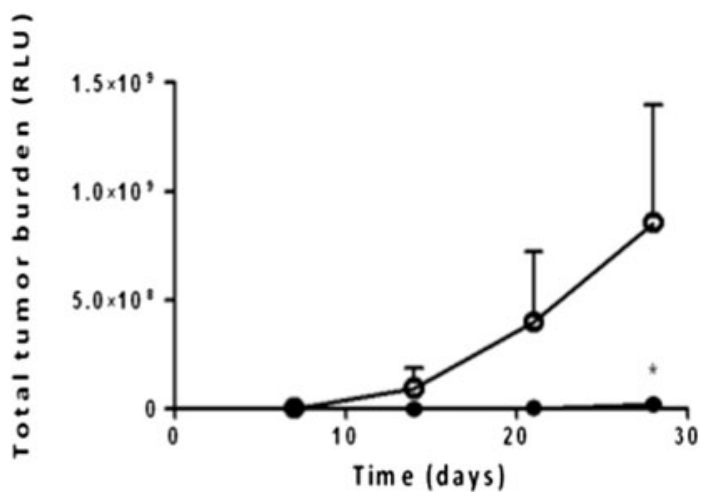

the NT-Pro4luc control population (open circles) ( $n=8$ /group). b Representative images of mice intra-osseously inoculated with either ALDH7A1-kd-Pro4luc or NT-Pro4luc cells $(100,000)$ at different days after inoculation. Total tumor burden of the mice injected with ALDH7A1-kd-Pro4luc (closed circles) or NT-Pro4luc cells (open circles) subpopulation $(n=8$ /group $* P<0.05)$

Our data suggest that ALDH7A1 is involved in many important processes in prostate cancer and support the notion that ALDH enzyme activity can be used to isolate prostate cancer stem/progenitor cells, although it remains to be established whether this isoform also plays a causal role in other human and mouse prostate cancer cell lines. Both EMT associated genes and stem/progenitor characteristics were negatively affected upon ALDH7A1 knockdown. The data presented in this article further substantiate the previously described association between EMT and cancer stem cells [4-8]. For instance, snail and twist expression were decreased in the ALDH7A1-kd-Pro4luc cells as compared to the NT-Pro4luc control cells. The pro-metastatic transcription factor and E-cadherin repressor twist was recently associated with EMT and the promotion of the tumor-initiating capability in carcinomas [35]. Twist expression was found to be linked to the generation of stem cell properties of cancer cells. The data presented in this article further extend and support this notion for prostate cancer, since ALDH7A1 knockdown decreased twist expression, leading to significant reductions in clonogenic properties and expression of prostate cancer stem cell markers. 


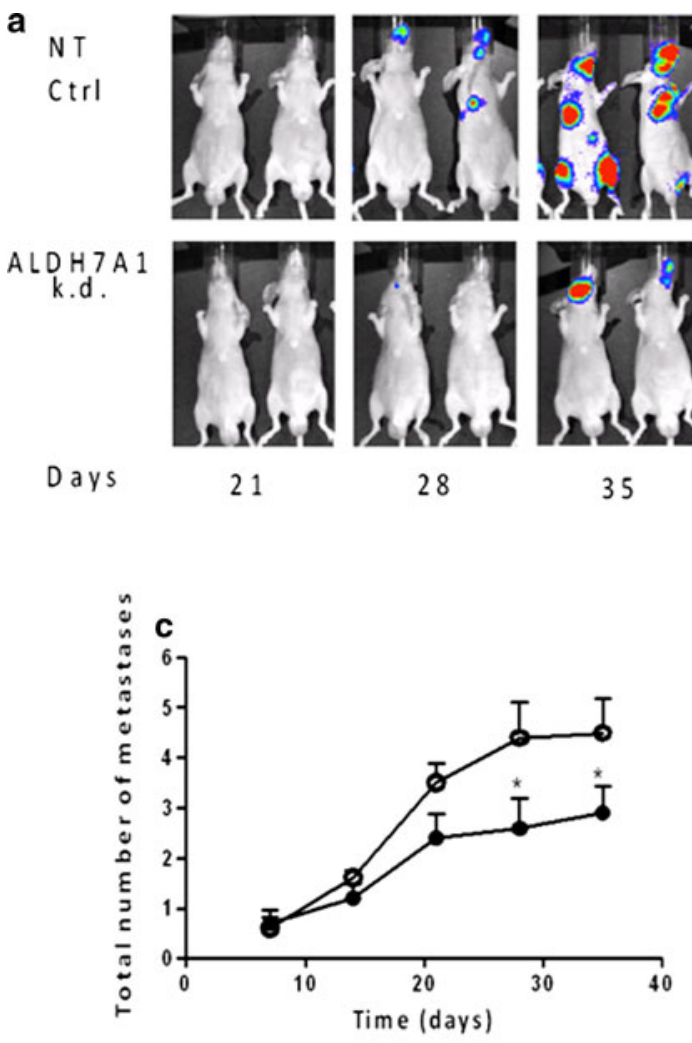

Fig. 4 ALDH7A1 knockdown prostate cancer cells show decreased metastatic growth in vivo. a Representative images of mice inoculated intra-cardiac with either 100,000 ALDH7A1-kd-Pro4luc knockdown or NT-Pro4luc control cells at day 21, 28, and 35 after inoculation ( $n=10$ /group). b Total tumor burden of ALDH7A1-kdPro4luc cells (closed circles) compared with NT-Pro4luc cells (open

Recently other studies have also provided evidence that EMT plays a critical role in the formation of bone metastases and a stem/progenitor cell phenotype [7, 42-44]. In cancer, EMT is fundamental for epithelial cells to become more invasive. We show here that ALDH7A1 is necessary for prostate cancer cells to acquire a metastatic phenotype and form bone metastases, but is not pivotal for growth at the orthotopic site. It appears that the bone microenvironment plays an important role and provides crucial factors for the tumor cells to grow. These data, therefore, provide further evidence for the role of the stroma in the regulation of tumor invasiveness and metastasis as was shown previously for BMP7 [36].

Osteoclasts resorb bone, thereby releasing growth factors like TGF- $\beta$ that may promote tumor cell proliferation, metastasis and survival, thus perpetuating a vicious cycle of tumor expansion and bone resorption [36, 45]. Strikingly, TGF- $\beta$ increased the ALDH ${ }^{\text {hi }}$ population as well as ALDH7A1 expression. One of the BMPs, BMP7, counteracts the pro-tumorigenic effects of TGF- $\beta$ [32], and decreased the $\mathrm{ALDH}^{\text {hi }}$ population and expression of ALDH7A1 in this study. This is in line with the notion that
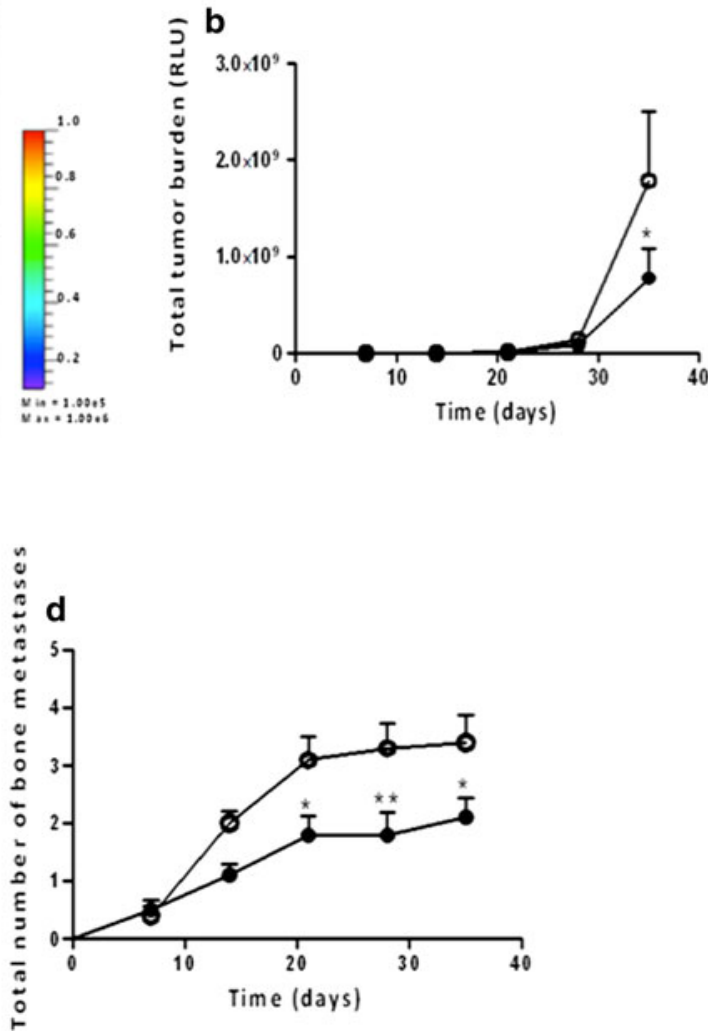

circles). c Total number of metastases per mouse in the mice injected with either ALDH7A1-kd-Pro4luc cells (closed circles) or NTPro4luc control cells (open circles). d Total number of bone metastases per mouse in the mice injected with either ALDH7A1kd-Pro4luc (closed circles) NT-Pro4luc control (open circles) cells

BMP7 induces differentiation towards a more epithelial, sessile tumor phenotype [32, 46-49]. In addition to TGF- $\beta$, OPN is prominently expressed at the sites of bone remodeling. Strikingly, TGF- $\beta$ can induce OPN expression in both bone and tumor cells $[50,51]$. Binding of OPN to the tumor cell membrane receptor CD44 can enhance tumor cell motility, migration and invasion in a paracrine and autocrine manner [52-55]. Knockdown of ALDH7A1 resulted in decreased OPN and CD44 expression in prostate cancer cells, which could explain, at least in part, a slowdown in intra-bone tumor growth and inhibition of (bone) metastasis formation.

In conclusion, we show that the ALDH7A1 enzyme may play a role in the formation of distant bone metastases. Downregulation of ALDH7A1 does not impair tumor growth at orthotopic sites but affects bone colonization and intra-osseous growth. This observed effect of ALDH7A1 expression suggests a pivotal role for the microenvironment and may be dependent on the presence of factors such as TGF- $\beta$ and OPN. Our studies show that stem/progenitor phenotype in human prostate cancer cells can be differentially affected by the ALDH7A1 enzyme and bone-active 

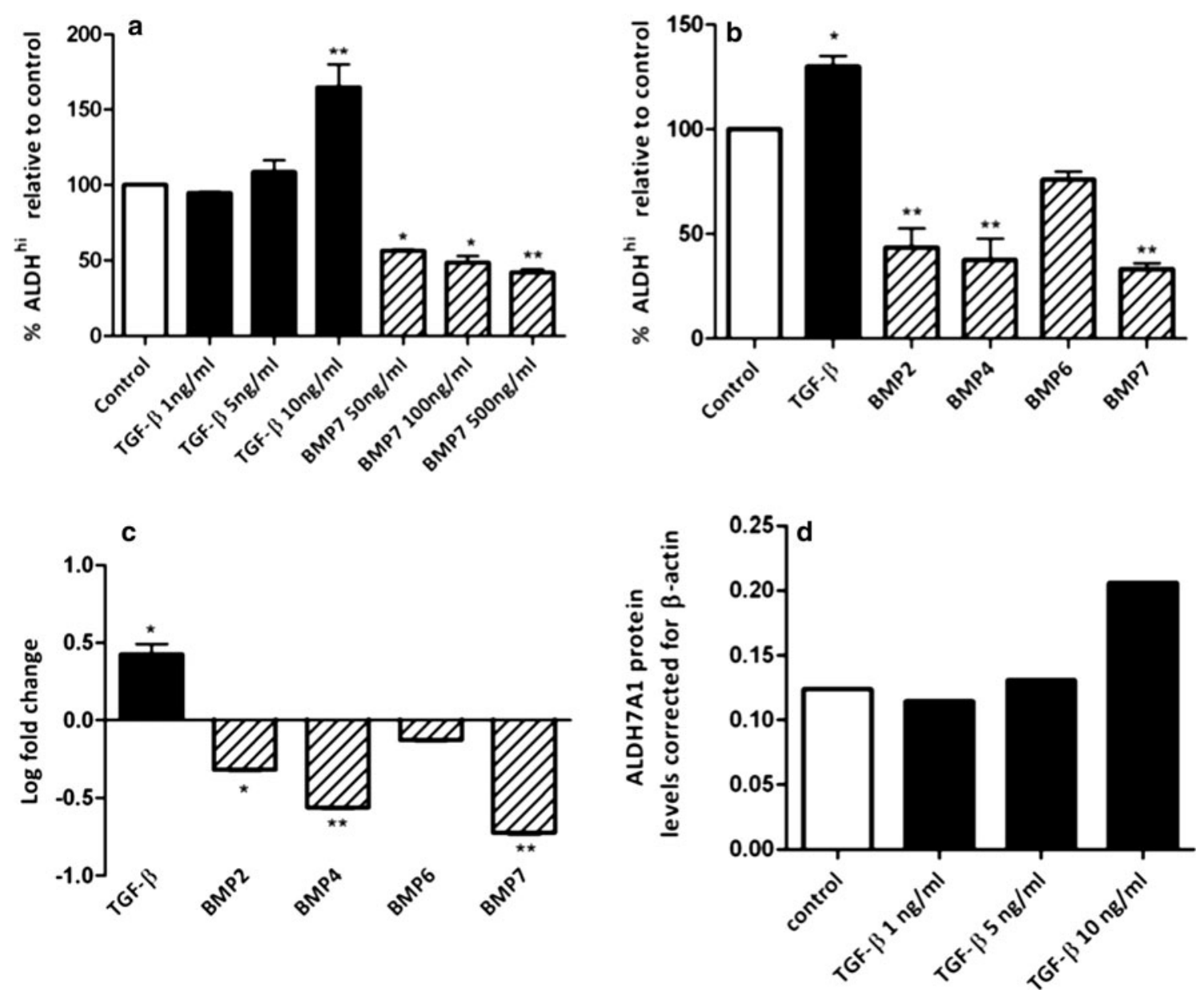

Fig. 5 Regulation of the PC-3M-Pro4luc subpopulation with high ALDH activity. a Human prostate cancer cells (PC-3M-Pro4luc) were assayed with the ALDEFLUOR ${ }^{\circledR}$ kit after stimulation for 3 days with different concentrations of either BMP7 $(50,100$, and $500 \mathrm{ng} / \mathrm{ml})$ or TGF- $\beta(1,5$, and $10 \mathrm{ng} / \mathrm{ml})$. b PC-3M-Pro4luc were assayed with the ALDEFLUOR $^{\circledR}$ kit after stimulation for 3 days with either BMPs (100 ng/ml BMP2, 4, 6, and $500 \mathrm{ng} / \mathrm{ml}$ BMP7) or $10 \mathrm{ng} / \mathrm{ml} \mathrm{TGF-} \beta$.

growth factors like TGF- $\beta$ and certain BMPs. Modulating and targeting this stem/progenitor subpopulation might be pivotal for the development of therapies for long-term disease-free survival.

\section{Methods}

Cell lines and culture conditions

The human prostate cancer cell line stably expressing firefly luciferase PC-3M-Pro4lucA6 (Pro4luc) was maintained in DMEM (GibcoBRL) containing $4.5 \mathrm{~g}$ glucose/l supplemented with $10 \%$ FCII, 100 units $/ \mathrm{ml}$ penicillin, $50 \mu \mathrm{g} / \mathrm{ml}$ streptomycin, and $800 \mu \mathrm{g} / \mathrm{ml}$ geneticin/G418 (Invitrogen) [36]. Puromycin in a concentration of $1 \mu \mathrm{g} / \mathrm{ml}$ was added for Pro4lucA6 with stable shRNAi knockdown.

c mRNA expression levels of ALDH7A1 in PC-3M-Pro4luc cells after stimulation for 3 days with either BMPs (BMP2, 4, 6, and 7) or TGF- $\beta$ as detected by qPCR. Data are representative for two independent experiments. d Western blot analysis of ALDH7A1 protein expression after stimulation of PC-3M-Pro4luc cells with TGF- $\beta$ for $72 \mathrm{~h}$. Intensities were normalized for $\beta$-actin

HEK293T cells were maintained in DMEM containing $10 \%$ FCS. All cell lines were grown in a humidified incubator at $37^{\circ} \mathrm{C}$ and $5 \% \mathrm{CO}_{2}$.

Suppressing ALDH7A1 expression

with a shRNA-lentiviral vector

Short hairpin RNAi constructs (ALDH7A1 clone\# TRCN 0000028463, TRCN0000028408 and TRCN0000028447) were derived from Sigma's MISSION library. HEK293T cells were transfected with the short hairpin constructs together with the packaging plasmids REV, GAG and VSV in a 1:1:1:1 ratio using Fugene HD (Roche) as transfection reagent. The supernatant of the culture medium containing the lentiviral vector was collected $48 \mathrm{~h}$ after transfection.

Pro4lucA6 cells were mixed with $1 \mathrm{ml}$ of shRNA-lentiviral vector and $8 \mu$ g Polybrene (Sigma) was added. The 
mixture was incubated for $1-2 \mathrm{~h}$ at room temperature. Scrambled shRNA (clone\# TRC1/1.5) was used as control which lack homology with any mammalian mRNA sequence. Cells stably expressing the shRNA were selected using puromycin $(1 \mu \mathrm{g} / \mathrm{ml}$, Sigma).

The ALDH7A1 knockdown cell line will further be referred to as ALDH7A1-kd-Pro4luc cells and the nontargeting control cell line as NT-Pro4luc cells.

\section{Western blot analysis}

Cells were washed with PBS and lysed in SDS-sample buffer (Laemmli buffer, Biorad). Proteins were separated on SDS-PAGE and subjected to Western blotting using standard techniques. Antibodies recognizing ALDH7A1 $(1: 5,000)$ was from Abcam and anti- $\beta$-actin $(1: 30,000)$ was from Sigma-Aldrich. Proteins were detected by using a chemiluminescence detection system from Roche.

\section{FACS analysis}

Expression of stem/progenitor- and EMT markers was measured by FACS analysis using the Calibur2 flow cytometer (BD Biosciences) and FCS express software (De Novo software USA). The cells $\left(1 \times 10^{5}\right.$ cells $)$ were incubated for $45 \mathrm{~min}$ at $4^{\circ} \mathrm{C}$ in a solution of $90 \mu \mathrm{l}$ FACS wash buffer containing PBS $+1 \%$ FCS $+0.1 \%$ natriumazide $\mathrm{NaN}_{3}$ and $10 \mu \mathrm{l}$ antibody ( $\alpha \mathrm{v}$-PE, $\alpha 2$-FITC, CD44APC, CD44v6-APC, Miltenyi). To determine $E$-cadherin/ vimentin ratios, cells were harvested and labeled with $E$-cadherin-FITC (BD Biosciences 1:10) in FACS buffer for $30 \mathrm{~min}$ at $4^{\circ} \mathrm{C}$ in the dark. Then cells were washed with $1 \mathrm{ml}$ FACS buffer and fixed with freshly prepared $2 \%$ formaldehyde for $15 \mathrm{~min}$. Cells were washed with ice cold PBS and subsequently incubated for $30 \mathrm{~min}$ at $4^{\circ} \mathrm{C}$ in the dark with vimentin rabbit polyclonal antibody (Abcam 1:200 in FACS buffer). Cells were washed twice with $1 \mathrm{ml}$ of FACS buffer and incubated for $30 \mathrm{~min}$ at $4{ }^{\circ} \mathrm{C}$ with goatanti rabbit IgG-APC antibody (Invitrogen). After the last incubation step, the cells were washed and centrifuged for 5 min followed by adding $250 \mu \mathrm{l}$ FACS wash buffer.

ALDH activity was measured as described earlier [4].

RNA isolation and real-time qPCR

RNA was extracted using Trizol (Invitrogen) according to manufacturer's instructions. Real-time qPCR was run and analyzed with a Biorad IQ5 cycler (Biorad). For primer sequences see Supplemental Table 1. Gene expression was measured relative to GAPDH expression using the following formula: Relative transcript abundance $(\mathrm{RTA})=$ $10,000 / 2^{\text {(Ctgene-CtGAPDH). }}$
Soft agar colony assay

Cell suspensions of both cell lines were generated (as described previously [4]) and overlayed onto a $60 \mathrm{~mm}$ dish containing a solidified bottom layer of $0.6 \%$ Noble agarose (Beckton Dickenson) in medium. One ml of medium was placed on top of the solidified cell layer. Plates were incubated for 1-3 weeks until colonies were visible. The colonies on the soft agar plates were counted by using light microscopy (Zeiss Axiovert 200M). Three individual and representative fields of each well were counted. The mean number of colonies/field was calculated.

\section{Colony forming assay}

Cells were seeded into a 96-wells plate containing an average of one cell per well. Plates were monitored twice a week and maintained in DMEM/10\% FCII medium. After 1-3 weeks colonies were clearly visible and the mean number of positive wells/plate was counted by microscopy (Zeiss Axiovert 200M).

\section{Migration assay}

Tumor cell migration was performed in transwell migration chambers (Costar) as described previously [4]. Three random fields were counted for each well, and mean numbers of migrated cells/field were calculated.

\section{Proliferation assay}

Cells were seeded at a density of $2,500 / \mathrm{cm}^{2}$ and allowed to grow for, respectively, 24, 48, and $72 \mathrm{~h}$. After the cell incubation, $20 \mu \mathrm{l}$ MTS was added to the medium and mitochondrial activity was measured at $490 \mathrm{~nm}$ after $2 \mathrm{~h}$ incubation at $37^{\circ} \mathrm{C}$ (CellTiter96 Aqueous non-radioactive cell proliferation assay (Promega)).

In vivo animal experiments

Mouse strains: Male nude (Balb/c nu/nu) mice were housed in individual ventilated cages under sterile condition according to the local guidelines for the care and use of laboratory animals (DEC07026 and 09052). Mice were anaesthetized before surgical and analytical procedures were performed.

Intra-osseous inoculation of Pro4luc cells: A single cell suspension of $1 \times 10^{5}$ ALDH7A1-kd-Pro4luc cells or NT-Pro4luc cells/10 $\mu \mathrm{l}$ PBS was injected into the right tibiae as described previously $[4,36,56]$. The progression of cancer cell growth was monitored weekly by BLI (whole body bioluminescent reporter imaging) as described below. 
Orthotopic inoculation of Pro4luc into the mouse prostate: A single cell suspension of $1 \times 10^{5}$ ALDH7A1kd-Pro4luc cells or NT-Pro4luc cells/10 $\mu \mathrm{l}$ PBS was combined with $10 \mu \mathrm{l}$ growth factor reduced matrigel (BD Biosciences) and surgically inoculated into the prostate of anaesthetized 6-week-old male nude mice [4, 48]. The progression of cancer cell growth was monitored weekly by BLI.

Intracardiac inoculation Pro4luc cells to induce systemic metastases: A single cell suspension of $1 \times 10^{5}$ ALDH7A1-kd-Pro4luc cells or NT-Pro4luc cells per $100 \mu \mathrm{lBS}$ was injected into the left cardiac ventricle of anaesthetized 5-week-old male nude mice and cancer cell growth was monitored weekly by BLI [4, 36].

Whole body bioluminescent reporter imaging (BLI) and quantification of the bioluminescent signal:

For all in vivo experiments, the progression of cancer cell growth was monitored weekly by bioluminescent imaging using the IVIS100 Imaging System (Caliper Life Science) as described earlier [36].

\section{Statistical analysis}

Statistical analysis was performed using GraphPad Prism 4.0 software $^{(}$(San Diego, CA) using either $t$-test (for comparison between two groups) or ANOVA (for comparison between more than two groups). Unless otherwise stated, data is presented as the mean \pm SEM. $P$ values of $\leq 0.05$ were regarded as being statistically significant $(* P<0.05, * * P<0.01, * * * P<0.001)$.

Open Access This article is distributed under the terms of the Creative Commons Attribution Noncommercial License which permits any noncommercial use, distribution, and reproduction in any medium, provided the original author(s) and source are credited.

\section{References}

1. Frydenberg M, Stricker PD, Kaye KW (1997) Prostate cancer diagnosis and management. Lancet 349:1681-1687

2. van der Pluijm G (2010) Epithelial plasticity, cancer stem cells and bone metastasis formation. Bone 48(1):37-43

3. Kalluri R, Weinberg RA (2009) The basics of epithelial-mesenchymal transition. J Clin Invest 119:1420-1428

4. van den Hoogen C, van der Horst G, Cheung H, Buijs JT, Lippitt JM, Guzman-Ramirez N, Hamdy FC, Eaton CL, Thalmann GN, Cecchini MG, Pelger RC, van der Pluijm G (2010) High aldehyde dehydrogenase activity identifies tumor-initiating and metastasisinitiating cells in human prostate cancer. Cancer Res 70: 5163-5173

5. Brabletz T, Jung A, Spaderna S, Hlubek F, Kirchner T (2005) Opinion: migrating cancer stem cells-an integrated concept of malignant tumour progression. Nat Rev Cancer 5:744-749

6. Kelly K, Yin JJ (2008) Prostate cancer and metastasis initiating stem cells. Cell Res 18:528-537
7. Mani SA, Guo W, Liao MJ, Eaton EN, Ayyanan A, Zhou AY, Brooks M, Reinhard F, Zhang CC, Shipitsin M, Campbell LL, Polyak K, Brisken C, Yang J, Weinberg RA (2008) The epithelial-mesenchymal transition generates cells with properties of stem cells. Cell 133:704-715

8. Morel AP, Lievre M, Thomas C, Hinkal G, Ansieau S, Puisieux A (2008) Generation of breast cancer stem cells through epithelialmesenchymal transition. PLoS One 3:e2888

9. Glinsky GV, Berezovska O, Glinskii AB (2005) Microarray analysis identifies a death-from-cancer signature predicting therapy failure in patients with multiple types of cancer. J Clin Invest 115:1503-1521

10. Li H, Chen X, Calhoun-Davis T, Claypool K, Tang DG (2008) PC3 human prostate carcinoma cell holoclones contain selfrenewing tumor-initiating cells. Cancer Res 68:1820-1825

11. Guzman-Ramirez N, Voller M, Wetterwald A, Germann M, Cross NA, Rentsch CA, Schalken J, Thalmann GN, Cecchini MG (2009) In vitro propagation and characterization of neoplastic stem/progenitor-like cells from human prostate cancer tissue. Prostate 69(15):1683-1693

12. Collins AT, Berry PA, Hyde C, Stower MJ, Maitland NJ (2005) Prospective identification of tumorigenic prostate cancer stem cells. Cancer Res 65:10946-10951

13. Clarke MF, Dick JE, Dirks PB, Eaves CJ, Jamieson CH, Jones DL, Visvader J, Weissman IL, Wahl GM (2006) Cancer stem cells-perspectives on current status and future directions: AACR workshop on cancer stem cells. Cancer Res 66:9339-9344

14. Fillmore C, Kuperwasser C (2007) Human breast cancer stem cell markers CD44 and CD24: enriching for cells with functional properties in mice or in man? Breast Cancer Res 9:303

15. Pfeiffer MJ, Schalken JA (2009) Stem cell characteristics in prostate cancer cell lines. Eur Urol 57:246-255

16. Eaton CL, Colombel M, van der Pluijm G, Cecchini M, Wetterwald A, Lippitt J, Rehman I, Hamdy F, Thalman G (2010) Evaluation of the frequency of putative prostate cancer stem cells in primary and metastatic prostate cancer. Prostate 70:875-882

17. Marchitti SA, Brocker C, Stagos D, Vasiliou V (2008) Non-P450 aldehyde oxidizing enzymes: the aldehyde dehydrogenase superfamily. Expert Opin Drug Metab Toxicol 4:697-720

18. Moreb JS, Mohuczy D, Ostmark B, Zucali JR (2007) RNAimediated knockdown of aldehyde dehydrogenase class-1A1 and class-3A1 is specific and reveals that each contributes equally to the resistance against 4-hydroperoxycyclophosphamide. Cancer Chemother Pharmacol 59:127-136

19. Moreb JS, Baker HV, Chang LJ, Amaya M, Lopez MC, Ostmark B, Chou W (2008) ALDH isozymes downregulation affects cell growth, cell motility and gene expression in lung cancer cells. Mol Cancer 7:87

20. Sladek NE, Kollander R, Sreerama L, Kiang DT (2002) Cellular levels of aldehyde dehydrogenases (ALDH1A1 and ALDH3A1) as predictors of therapeutic responses to cyclophosphamide-based chemotherapy of breast cancer: a retrospective study. Rational individualization of oxazaphosphorine-based cancer chemotherapeutic regimens. Cancer Chemother Pharmacol 49:309-321

21. Vasiliou V, Pappa A (2000) Polymorphisms of human aldehyde dehydrogenases. Consequences for drug metabolism and disease. Pharmacology 61:192-198

22. Huang EH, Hynes MJ, Zhang T, Ginestier C, Dontu G, Appelman H, Fields JZ, Wicha MS, Boman BM (2009) Aldehyde dehydrogenase 1 is a marker for normal and malignant human colonic stem cells (SC) and tracks SC overpopulation during colon tumorigenesis. Cancer Res 69:3382-3389

23. Ginestier C, Hur MH, Charafe-Jauffret E, Monville F, Dutcher J, Brown M, Jacquemier J, Viens P, Kleer CG, Liu S, Schott A, Hayes D, Birnbaum D, Wicha MS, Dontu G (2007) ALDH1 is a 
marker of normal and malignant human mammary stem cells and a predictor of poor clinical outcome. Cell Stem Cell 1:555-567

24. Pearce DJ, Taussig D, Simpson C, Allen K, Rohatiner AZ, Lister TA, Bonnet D (2005) Characterization of cells with a high aldehyde dehydrogenase activity from cord blood and acute myeloid leukemia samples. Stem Cells 23:752-760

25. Jelski W, Szmitkowski M (2008) Alcohol dehydrogenase (ADH) and aldehyde dehydrogenase (ALDH) in the cancer diseases. Clin Chim Acta 395:1-5

26. Ucar D, Cogle CR, Zucali JR, Ostmark B, Scott EW, Zori R, Gray BA, Moreb JS (2009) Aldehyde dehydrogenase activity as a functional marker for lung cancer. Chem Biol Interact 178:48-55

27. Croker AK, Goodale D, Chu J, Postenka C, Hedley BD, Hess DA, Allan AL (2008) High aldehyde dehydrogenase and expression of cancer stem cell markers selects for breast cancer cells with enhanced malignant and metastatic ability. J Cell Mol Med $13: 2236-2252$

28. Charafe-Jauffret E, Ginestier C, Iovino F, Tarpin C, Diebel M, Esterni B, Houvenaeghel G, Extra JM, Bertucci F, Jacquemier J, Xerri L, Dontu G, Stassi G, Xiao Y, Barsky SH, Birnbaum D, Viens P, Wicha MS (2010) Aldehyde dehydrogenase 1-positive cancer stem cells mediate metastasis and poor clinical outcome in inflammatory breast cancer. Clin Cancer Res 16:45-55

29. Su Y, Qiu Q, Zhang X, Jiang Z, Leng Q, Liu Z, Stass SA, Jiang F (2010) Aldehyde dehydrogenase 1 A1-positive cell population is enriched in tumor-initiating cells and associated with progression of bladder cancer. Cancer Epidemiol Biomarkers Prev 19:327-337

30. Li T, Su Y, Mei Y, Leng Q, Leng B, Liu Z, Stass SA, Jiang F (2009) ALDH1A1 is a marker for malignant prostate stem cells and predictor of prostate cancer patients' outcome. Lab Invest 90(2):234-244

31. Marcato P, Dean CA, Pan D, Araslanova R, Gillis M, Joshi M, Helyer L, Pan L, Leidal A, Gujar S, Giacomantonio CA, Lee PW (2010) Aldehyde dehydrogenase activity of breast cancer stem cells is primarily due to isoform ALDH1A3 and its expression is predictive of metastasis. Stem Cells 29(1):32-45

32. Buijs JT, Henriquez NV, van Overveld PG, van der Horst G, Ten Dijke P, van der Pluijm G (2007) TGF-beta and BMP7 interactions in tumour progression and bone metastasis. Clin Exp Metastasis 24:609-617

33. Cheung AM, Wan TS, Leung JC, Chan LY, Huang H, Kwong YL, Liang R, Leung AY (2007) Aldehyde dehydrogenase activity in leukemic blasts defines a subgroup of acute myeloid leukemia with adverse prognosis and superior NOD/SCID engrafting potential. Leukemia 21:1423-1430

34. Tanaka H, Kono E, Tran CP, Miyazaki H, Yamashiro J, Shimomura T, Fazli L, Wada R, Huang J, Vessella RL, An J, Horvath S, Gleave M, Rettig MB, Wainberg ZA, Reiter RE (2010) Monoclonal antibody targeting of $N$-cadherin inhibits prostate cancer growth, metastasis and castration resistance. Nat Med 16(12):1414-1420

35. Yang MH, Hsu DS, Wang HW, Wang HJ, Lan HY, Yang WH, Huang CH, Kao SY, Tzeng CH, Tai SK, Chang SY, Lee OK, Wu KJ (2010) Bmi1 is essential in Twist1-induced epithelial-mesenchymal transition. Nat Cell Biol 12:982-992

36. Buijs JT, Rentsch CA, van der Horst G, van Overveld PG, Wetterwald A, Schwaninger R, Henriquez NV, Ten Dijke P, Borovecki F, Markwalder R, Thalmann GN, Papapoulos SE, Pelger RC, Vukicevic S, Cecchini MG, Lowik CW, van der Pluijm G (2007) BMP7, a putative regulator of epithelial homeostasis in the human prostate, is a potent inhibitor of prostate cancer bone metastasis in vivo. Am J Pathol 171:1047-1057

37. Yu C, Yao Z, Dai J, Zhang H, Escara-Wilke J, Zhang X, Keller ET (2011) ALDH activity indicates increased tumorigenic cells, but not cancer stem cells, in prostate cancer cell lines. In Vivo 25:69-76

38. Patrawala L, Calhoun T, Schneider-Broussard R, Li H, Bhatia B, Tang S, Reilly JG, Chandra D, Zhou J, Claypool K, Coghlan L, Tang DG (2006) Highly purified CD44+ prostate cancer cells from xenograft human tumors are enriched in tumorigenic and metastatic progenitor cells. Oncogene 25:1696-1708

39. Birnie R, Bryce SD, Roome C, Dussupt V, Droop A, Lang SH, Berry PA, Hyde CF, Lewis JL, Stower MJ, Maitland NJ, Collins AT (2008) Gene expression profiling of human prostate cancer stem cells reveals a pro-inflammatory phenotype and the importance of extracellular matrix interactions. Genome Biol 9:R83

40. Collins AT, Habib FK, Maitland NJ, Neal DE (2001) Identification and isolation of human prostate epithelial stem cells based on alpha(2)beta(1)-integrin expression. J Cell Sci 114:3865-3872

41. Cooper CR, Chay CH, Pienta KJ (2002) The role of alpha(v)beta(3) in prostate cancer progression. Neoplasia 4:191-194

42. Kasper S (2009) Identification, characterization, and biological relevance of prostate cancer stem cells from clinical specimens. Urol Oncol 27:301-303

43. Kong D, Banerjee S, Ahmad A, Li Y, Wang Z, Sethi S, Sarkar FH (2010) Epithelial to mesenchymal transition is mechanistically linked with stem cell signatures in prostate cancer cells. PLoS One 5:e12445

44. Santisteban M, Reiman JM, Asiedu MK, Behrens MD, Nassar A, Kalli KR, Haluska P, Ingle JN, Hartmann LC, Manjili MH, Radisky DC, Ferrone S, Knutson KL (2009) Immune-induced epithelial to mesenchymal transition in vivo generates breast cancer stem cells. Cancer Res 69:2887-2895

45. van der Pluijm G, Que I, Sijmons B, Buijs JT, Lowik CW, Wetterwald A, Thalmann GN, Papapoulos SE, Cecchini MG (2005) Interference with the microenvironmental support impairs the de novo formation of bone metastases in vivo. Cancer Res 65:7682-7690

46. Na YR, Seok SH, Kim DJ, Han JH, Kim TH, Jung H, Lee BH, Park JH (2009) Bone morphogenetic protein 7 induces mesenchymal-to-epithelial transition in melanoma cells, leading to inhibition of metastasis. Cancer Sci 100:2218-2225

47. Zeisberg M, Shah AA, Kalluri R (2005) Bone morphogenic protein-7 induces mesenchymal to epithelial transition in adult renal fibroblasts and facilitates regeneration of injured kidney. J Biol Chem 280:8094-8100

48. Buijs JT, Henriquez NV, van Overveld PG, van der Horst G, Que I, Schwaninger R, Rentsch C, Ten Dijke P, Cleton-Jansen AM, Driouch K, Lidereau R, Bachelier R, Vukicevic S, Clezardin P, Papapoulos SE, Cecchini MG, Lowik CW, van der Pluijm G (2007) Bone morphogenetic protein 7 in the development and treatment of bone metastases from breast cancer. Cancer Res 67:8742-8751

49. Li F, Tiede B, Massague J, Kang Y (2007) Beyond tumorigenesis: cancer stem cells in metastasis. Cell Res 17:3-14

50. Noda M, Yoon K, Prince CW, Butler WT, Rodan GA (1988) Transcriptional regulation of osteopontin production in rat osteosarcoma cells by type beta transforming growth factor. J Biol Chem 263:13916-13921

51. Hullinger TG, Pan Q, Viswanathan HL, Somerman MJ (2001) TGFbeta and BMP-2 activation of the OPN promoter: roles of smad- and hox-binding elements. Exp Cell Res 262:69-74

52. Rangaswami H, Bulbule A, Kundu GC (2006) Osteopontin: role in cell signaling and cancer progression. Trends Cell Biol 16:79-87

53. Wai PY, Kuo PC (2004) The role of osteopontin in tumor metastasis. J Surg Res 121:228-241

54. Bellahcene A, Castronovo V, Ogbureke KU, Fisher LW, Fedarko NS (2008) Small integrin-binding ligand $N$-linked glycoproteins 
(SIBLINGs): multifunctional proteins in cancer. Nat Rev Cancer 8:212-226

55. Chakraborty G, Jain S, Kundu GC (2008) Osteopontin promotes vascular endothelial growth factor-dependent breast tumor growth and angiogenesis via autocrine and paracrine mechanisms. Cancer Res 68:152-161
56. Wetterwald A, van der Pluijm G, Que I, Sijmons B, Buijs J, Karperien M, Lowik CW, Gautschi E, Thalmann GN, Cecchini MG (2002) Optical imaging of cancer metastasis to bone marrow: a mouse model of minimal residual disease. Am J Pathol 160:1143-1153 